\title{
Common brain regions essential for the expression of learned and instinctive visual habits in the albino rat*
}

\author{
ROBERT THOMPSON and JOSEPH E. LEDOUX \\ Louisiana State University, Baton Rouge, Louisiana 70803
}

\begin{abstract}
Different groups of adult rats were subjected to discrete lesions in one of ten different areas of the brain which have previously been found to be implicated in retention of learned brightness and pattern discrimination habits. When tested for the rodent's predictable (instinctive) preference for the dark, eight groups showed deficient preference scores and two showed preference scores comparable to that of the control group. Those groups with lesions of brain structures not implicated in retention of learned visual discrimination habits exhibited normal preference scores. These data suggest the existence of common as well as diverse neuroanatomical substrata necessary for the expression of both classes of adaptive behavior.
\end{abstract}

Are those anatomical areas of the brain which are necessary for the expression of learned habits also necessary for the expression of instinctive (species predictable) habits? According to Hebb (1953, 1966), commonality of anatomical sites must exist as evidenced, for example, by the importance of the cerebral cortex in maze learning (Lashley, 1929), on the one hand, and in copulatory and maternal behaviors (Beach, 1937, 1940), on the other. Hebb's view of this problem, however, has not been shared, at least explicitly, by other contemporary neuroscientists. Generally, the nervous structures concerned with instinctive behavior patterns are thought to inhabit the brainstem of higher animals, while those subserving learned behavior patterns are thought to occupy the limbic system, neocortex, or both. This alternate view has most recently been expressed in the theory of the "triune brain" (MacLean, 1970).

An intensive investigation of this problem has not heretofore been attempted because it hinges upon the identification of those cortical and subcortical structures critically participating in the performance of previously learned habits. This prerequisite has recently been fulfilled in a series of lesion studies (Thompson, 1969; Thompson, Chetta, \& LeDoux, 1974; Thompson \& Pucheu, 1973; Thompson \& Thorne, 1973) on the albino rat which has led to the mapping of the "visual memory system"-that ensemble of nervous sites which are essential for the expression of learned visual (brightness and pattern) discrimination habits. These sites include the retino-geniculo-striate complex, globus pallidus, posterolateral hypothalamus, subthalamus, pretecto-diencephalon (nucleus pretectalis, posterior, and parafascicularis), rostral extension of the reticular formation at the dimesencephalic juncture, red nucleus

\footnotetext{
*This research was supported in part by a grant from the Graduate Council of Research, Louisiana State University.
}

area, central tegmental area (interpeduncular nucleus and raphe nuclei), ventrolateral midbrain area (substantia nigra and overlying tegmentum), and the nucleus reticularis pontis oralis. The purpose of the current study was to determine whether damage to any one of the foregoing regions making up the visual memory system would interfere with the expression of a species predictable visual preference exhibited by the albino rat; namely, the preference for a dark compartment over an illuminated compartment. ${ }^{1}$

\section{METHOD}

The apparatus consisted of a two-compartment box having a grid floor. The walls were $20.5 \mathrm{~cm}$ high and painted flat white The large illuminated compartment, which measured $47.6 \mathrm{~cm}$ long and $41.0 \mathrm{~cm}$ wide, was covered by a transparent plastic lid. The small dark compartment measuring $33.3 \mathrm{~cm}$ long and $24.1 \mathrm{~cm}$ wide was covered by a plastic lid painted flat black on the outside. An opening (10.2 cm square) at one end of the illuminated compartment gave access to the dark compartment. The entire apparatus was located in a room illuminated by conventional ceiling fluorescent lights. During testing, an opaque white screen with a small aperture for viewing was secured to one wall of the apparatus.

The test consisted of placing an individual rat into the illuminated compartment at a point maximally distant from the dark compartment and observing the rat for $10 \mathrm{~min}$. (In most cases, the test was done "blind"-the $\mathrm{O}$ had no knowledge of either the presence or locus of the lesion). Latency to enter the dark compartment, the number of exits from the dark compartment, and the total amount of time spent in the dark compartment were recorded. Entrances into (or exits from) the dark compartment were scored only when $S$ placed all four legs within (or outside of) the dark compartment. The floor and sides of the apparatus were routinely cleaned after testing each $S$.

In the main experiment, the Ss were adult male albino rats of the Wistar strain that underwent either brain damage or sham operations (control group) 7 to 14 days prior to the test. An attempt was made to produce lesions in various parts of the visual memory system which were similar in magnitude and locus to those previously reported to have amnestic effects on visual discrimination habits. As a control for the presence of brain 
damage, four additional groups underwent lesions of either frontal cortex, caudate nucleus, superior colliculus, or lateral thalamus. These structures lie outside of the visual memory system (see Thompson, 1969; Thompson et al, 1974). Following the test, verification of the locus and extent of the lesions was carried out.

\section{RESULTS}

Table 1 summarizes the results of the main experiment. $^{2}$ One index of preference for the dark can be expressed in terms of percentage amount of time spent in the dark compartment after initial entry into the dark compartment. As shown in Table 1, the groups sustaining lesions to those structures outside of the visual memory system earned mean preference scores which were slightly, though not significantly, higher than that earned by the control group. With respect to those groups sustaining lesions within the visual memory system, only those with pallidal or hypothalamic damage earned scores comparable to that of the control group. Significantly lower preference scores were earned by the groups having either visual cortical, pretecto-diencephalic, rostral reticular formation, or central tegmental area lesions. While the mean preference scores of the remaining groups having lesions to the visual memory system fell short of statistical significance, it is important to note that at least half of the Ss within each of these groups earned preference scores below $80 \%$-of the 14 Ss involved, nine scored below $80 \%$. When compared either to the sham operated Ss (only three scored below $80 \%$ ) or to the brain-damaged Ss making up the extravisual memory system groups (only two scored below 80\%), the difference was significant ( $p s=.05$, Fisher exact probability test).

Table 1

Mean Preference Scores for All Groups

\begin{tabular}{|c|c|c|c|}
\hline Lesion & $\begin{array}{l}\mathrm{Pe} \\
\mathrm{C}\end{array}$ & $\begin{array}{l}\text { Percent Time } \\
\text { in Dark } \\
\text { Compartment }\end{array}$ & $\begin{array}{c}\text { Number } \\
\text { of } \\
\text { Exits }\end{array}$ \\
\hline \multicolumn{4}{|c|}{ Sham Operated Group } \\
\hline None & 13 & 90.7 & 2.8 \\
\hline \multicolumn{4}{|c|}{ Extravisual Memory System Groups } \\
\hline Frontal cortex & 4 & 99.6 & .3 \\
\hline Caudate nucleus & 4 & 91.4 & 3.3 \\
\hline Lateral thalamus & 3 & 96.0 & .7 \\
\hline Superior colliculus & 4 & 96.8 & 1.8 \\
\hline \multicolumn{4}{|c|}{ Visual Memory System Groups } \\
\hline Visual cortex & 4 & $42.6^{*}$ & $6.0^{*}$ \\
\hline Globus pallidus & 2 & 91.8 & 3.0 \\
\hline Posterolateral hypothalamus & 3 & 94.8 & .7 \\
\hline Subthalamus & 4 & 77.3 & 4.3 \\
\hline Pretecto-diencephalon & 5 & $50.1 * *$ & 5.4 \\
\hline Rostral reticular formation & 2 & $50.3 * * *$ & 5.5 \\
\hline Ventrolateral midbrain area & 3 & 80.3 & 6.7 \\
\hline Central tegmental area & 3 & $55.4^{*}$ & $25.2 *$ \\
\hline Red nucleus area & 4 & 80.3 & 6.0 \\
\hline Nucleus reticularis pontis oralis & 3 & 78.8 & $13.0^{*}$ \\
\hline
\end{tabular}

Note-All ps by Mann-Whitney (1947) test.

$$
{ }^{*} p=.01 \quad{ }^{* *} p=.025 \quad * * p=.05
$$

It might be expected that the number of exits from the dark compartment would also reflect the strength of the preference for the dark-the fewer the exits, the stronger the preference. As noted in Table 1, the number of exits exhibited by the groups with extravisual memory system damage was either comparable to or slightly less than that exhibited by the control group. Concerning the Ss with damage to the visual memory system, only the pallidal and hypothalamic groups exhibited scores which failed to reflect a decrement in preference for the dark. Significant increases in the frequency of exits were found in those groups sustaining lesions to either the visual cortex, central tegmental area, or nucleus reticularis pontis oralis. Again, it should be pointed out that at least half of the Ss within each of the remaining groups having lesions to the visual memory system exited more than five times from the dark compartment-of the $18 \mathrm{Ss}$ involved, 10 exited more than five times. When compared either to the control Ss (only two exited more than five times) or to the brain-damaged Ss composing the extravisual memory system groups (only two exited more than five times), the difference was significant ( $\mathrm{ps}<.05, \chi^{2}$ test).

\section{DISCUSSION}

The overall results suggest the existence of at least five overlapping nervous regions (visual cortex, pretecto-diencephalon, rostral reticular formation, central tegmental area, and nucleus reticularis pontis oralis) in the rodent's brain which are involved in the expression of both learned and instinctive behaviors "released" by visual stimuli. Three additional areas of overlap (subthalamus, red nucleus area, and ventrolateral midbrain area) may exist, but require further study. Thus, this portion of the results supports Hebb's view to the extent that commonality of nervous sites does exist in the regulation of both classes of adaptive behavior. However, the findings in relation to the globus pallidus and posterolateral hypothalamus suggest that diverse anatomical mechanisms may also be involved in the expression of each class of adaptive behavior.

Although other interpretations are possible, it is suggested that the lesion-induced deficits seen on both classes of adaptive behavior have a common basis; namely, the interference with the expression (or the disruption) of associations between visual stimuli and an emotion (see Mowrer, 1960). With respect to the rat's preference for the dark, the visually elicited emotion would be fear. In the case of a learned visual discrimination habit, the visually-elicited emotion would either be fear (when the response to the negative card is punished) or frustration (when the response to the negative card is simply nonrewarded). The precise nature of this interference induced by each lesion must await further studies.

\section{REFERENCES}

Beach, F. A. The neural basis of innate behavior. I. Effects of cortical lesions upon the maternal behavior pattern in the rat. Journal of Comparative Psychology, 1937, 24, 93-436.

Beach, F. A. Effects of cortical lesions upon the copulatory behavior of male rats. Journal of Comparative Psychology, $1940,29,193-239$.

Hebb, D. O. Heredity and environment in mammalian behavior. British Journal of Animal Behavior, 1953, 1, 43-47.

Hebb, D. O. A textbook of psychology. Philadelphia: Saunders, 1966 .

Lashley, K. S. Brain mechanisms and intelligence. Chicago: University of Chicago Press, 1929. 
MacLean, P. D. The triune brain, emotion, and scientific bias. In F. O, Schmitt (Ed.), The neurosciences. New York: Rockefellar University Press, 1970.

Mann, H. B., \& Whitney, D. R. On a test of whether one or two random variables is stochastically larger than the other. Annals of Mathem atical Statistics, 1947, 18, 50-60.

Mowrer, O. H. Learning theory and behavior. New York: Wiley, 1960.

Thompson, R. Localization of the "visual memory system" in the white rat. Journal of Comparative \& Physiological Psychology Monograph, 1969, 69, Part 2, 1-29.

Thompson, R., Chetta, H., \& DeDoux, J. E. Brightness discrimination loss after lesions of the corpus striatum in the white rat. Bulletin of the Psychonomic Society, 1974, 3, 293-295.

Thompson, R., \& Pucheu, J. H. Disconnecting reticulocortical pathways: Amnestic effects on visual habits in the rat. Bulletin of the Psychonomic Society, 1973, 2, 165-166.
Thompson, R., \& Thorne, B. M. Brainstem reticular formation lesions: Amnestic effects on learned habits in the rat. Physiological Psychology, 1973, 1, 61-70.

\section{NOTES}

1. Preliminary experiments in our laboratory revealed that the normal adult male albino rat spends from $70 \%-100 \%$ of the time in the dark compartment, that this preference is reduced to less than $50 \%$ following enucleation of the eyes, and that this preference is present in infant rats 1 day after weaning, but does not reach adult proportions until about 37 days of age.

2. Three rats with pallidal, two with hypothalamic, one with pretecto-diencephalic, and one with rostral reticular formation lesions failed to enter the dark compartment within $10 \mathrm{~min}$. Their results were discarded from the analysis.

(Received for publication June 14, 1974.)

\title{
The nature of affective bonds and the degree of personal responsibility as determinants of risk taking for "self and others"*

\author{
YOEL YINON and AHARON BIZMAN \\ Bar Ilan University, Ramat-Gan, Israel
}

\begin{abstract}
The hypotheses that (1) the nature of affective bonds among group members, and (2) the degree of personal responsibility for decisions made for "self and others" were determinants of the level of risk taken in making these decisions were tested in a field experiment. Ninety boys, aged 16-18, who were residents of a dormitory, made decisions in a card game which affected both themslves and two others. These triads consisted of boys who mu tually (1) liked each other, (2) were indifferent to each other, and (3) disliked each other. It was found that Ss in the cohesive triads took fewer risks than members of the indifferent or hostile triads. Ss under a personal responsibility condition tended to take fewer risks than did Ss under a group responsibility condition. Contrary to expectation, no interaction was found between the two variables. The results were explained in terms of the living circumstances of the Ss.
\end{abstract}

One of the explanations offered in order to account for the risky shift phenomenon is the "affective-bonds" hypothesis, suggested by Wallach and Kogan (1965), as a modification of the earlier diffusion of responsibility hypothesis. They suggest that during group discussion, affective bonds are developed among group members, such that the feeling of personal responsibility for a potential negative outcome of a risky action is reduced.

*This paper is sponsored by Marvin E. Shaw, who takes full editorial responsibility for its contents. The authors are grateful to A. Kuper, M. Even-Chen, and S. Peled, who ran the experiment.
Therefore, groups are willing to take higher risks than are the individuals who comprise them.

In a recent study, Dion, Miller, and Magnan (1971) manipulated group cohesiveness and hypothesized a larger risky shift under the high- than under the low-cohesiveness condition. The results proved to be counter to the affective bonds hypothesis showing a reduced risky shift under the high-cohesiveness condition. Nevertheless, this finding was interpreted by the authors, in a post facto manner, as supporting the diffusion of responsibility hypothesis.

They suggest that strong affective bonds make 